\title{
Influence of Chemical Composite Additive on Combustion and Emission Characteristics of a Diesel Engine using Waste Plastic Oil as Fuel and Modified Piston Bowl
}

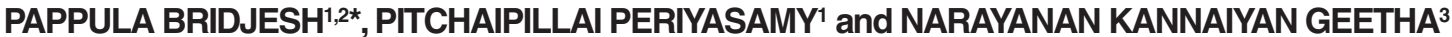

\author{
'Department of Mechanical Engineering, St. Peter's Institute of Higher Education \& Research, \\ Chennai 600054, India. \\ ${ }^{2}$ Department of Mechanical Engineering, MLR Institute of Technology, Hyderabad 500043, India. \\ ${ }^{3}$ Department of Science and Humanities, Sri Krishna College of Engineering and Technology, \\ Coimbatore 641008, India. \\ ${ }^{*}$ Corresponding author E-mail: meetbridjesh @ gmail.com
}

http://dx.doi.org/10.13005/ojc/340617

Received: September 19, 2018; Accepted: November 07, 2018)

\begin{abstract}
This experimental investigation is an endeavour to substitute diesel with WPO as fuel on a diesel engine. Enhancing the physiochemical properties of WPO or with hardware modifications on the engine, the performance of engine could not be improved up to the mark. The physiochemical properties of WPO are enhanced by the use of composite additive, which is a mixture of soy lecithin and 2-ethylhexyl nitrate and to improve the in-cylinder air motion; subsequently to increase the swirl and turbulence, standard hemispherical combustion chamber is modified to toroidal spherical grooves combustion chamber. The results of combined effect of modifying the combustion chamber and addition of composite additive suggest that improvements in engine-out emissions can be obtained from current diesel engines by enhancing physiochemical properties of fuel and matching geometry of combustion chamber. Engine combustion and emission characteristics under various loads for various fuels under test are as well studied.
\end{abstract}

Keywords: Waste plastic oil(WPO), Pyrolysis, Soy lecithin, 2-ethylhexyl nitrate, Toroidal spherical groove, Composite additive.

\section{INTRODUCTION}

Amid late years, diesel engines have been broadly used for commercial vehicles as well as for passenger cars apart from off-road applications. The direct injection diesel engines are of much interest in wide applications due to their low fuel consumption, durability and improved reliability. However, the future of this success is threatened by the concerns on environment ${ }^{1}$ and depletion of fossil fuels ${ }^{2}$. As a result, the quest for alternative fuels has quickened.
Waste management policies ${ }^{3}$ and global warming ${ }^{4,5}$ can be addressed simultaneously by producing fuel from plastic wastes 6 . The oil produced from plastic wastes is termed as waste plastic oil (WPO). As the raw material cost for production of WPO is zero, it is acclaimed to be a promising alternative fuel. Many researchers have proclaimed that the properties of WPO are close to diese $\mathrm{P}^{7,8}$. Further, they have investigated WPO as fuel on diesel engines either by blending or by adding additives.

This is an Open Access article licensed under a Creative Commons license: Attribution 4.0 International (CC- BY). Published by Oriental Scientific Publishing Company @ 2018 
Research established by ${ }^{9}$ using diethyl ether with WPO blends resulted in decreased brake thermal efficiency (BTE) along with oxides of nitrogen $\left(\mathrm{NO}_{\mathrm{x}}\right)$. However, brake specific fuel consumption (BSFC), hydro carbon $(\mathrm{HC})$ and carbon-monoxide (CO) increased than diesel. Vis-à-vis, the research established by ${ }^{10}$ using $n$-butanol showed favorable results in terms of spray characteristics. But $\mathrm{NO}_{x}$ emission increases with increase in volume of $n$-butanol. Methoxyethyl acetate as additive to WPO-diesel favored in lessening smoke, $\mathrm{HC}$ and $\mathrm{CO}$ with penalty in $\mathrm{NO}_{x}{ }^{11}$.

The utilization of neat WPO in engine demonstrated very much clashing outcomes in performance combustion and emission along with engine lifespan. Challenges in using WPO as fuel are low cetane number, low calorific value, poor atomization, high aromatic content and high viscosity along with injector hole deposits. Apart from that, the delay period is increased during combustion with neat WPO. And these challenges unfavorably influence the performance and emissions.

Despite the higher efficiency, diesel engines emit higher $\mathrm{NO}_{x}$ and soot emissions. In an attempt to mitigate these emissions, trade off between $\mathrm{NO}_{\mathrm{x}}$ and $\mathrm{HC}$ props up that always influenced the design of engines. The injected fuel has to atomize vaporize and mix properly with air so as to attain better combustion which can be achieved either by modification of the geometry of the combustion chamber or by increasing the fuel injection pressure. In employing high pressure injector, major modifications are needed on the engine. High swirl induced pistons enhances turbulence ${ }^{12}$. It is evitable that the combustion quality is significantly influenced by the charge motion inside the engine cylinder. Accordingly, the combustion chamber geometry has been considered as an incredible plan in incrementing efficiency and emanation lessening. Numerical investigation carried out by ${ }^{13}$ revealed that better squish and high heat release rate (HRR) can be acquired with smaller bowl size. However, performance of engine was adversely affected by increasing piston bowl radius. Out of the various combustion chamber profiles like toroidal combustion chamber, mexican hat combustion chamber, double lip combustion chamber and bow combustion chamber it was investigated numerically that turbulence was greatly enhanced with toroidal combustion chamber profile ${ }^{14}$.

It is clear from the above literature that either enhancing the physiochemical properties of WPO or hardware modifications on the engine could not improve the performance of the engine with neat WPO. These issues motivated the authors to look for composite additive to enhance those properties of WPO which are inferior to diesel and also to modify the geometry of piston bowl. The aim of this study is to explore combined effect of modifying piston bowl and addition of composite additive to WPO on combustion performance alongside emission characteristics of single cylinder diesel engine.

\section{MATERIALS AND METHODS}

WPO is extracted from plastic wastes constituting polyethylene with high and low density, terephthalate polyethylene and polypropylene using pyrolysis process. Plastic wastes are cut into little bits of size $1-2 \mathrm{~cm}^{2}$ and washed incessantly with water and then dried. Those plastic bits are taken into a reactor to undergo pyrolysis in presence of nitrogen gas, which acts as a fluidizing agent. Fluid catalytic cracking catalyst was used not only to reduce the optimum temperature of pyrolysis but also to enhance hydrocarbon dissemination in pyrolysis. Catalyst to polymer ratio of $20 \mathrm{wt} \%$ was used in the process for higher yield. Fluid catalytic cracking catalyst was subjected to mild steaming at $750^{\circ} \mathrm{C}$ for $5 \mathrm{~h}$ to increase the production of diesel fraction in WPO. PID controller maintains temperature in reactor between 300-4500 $\mathrm{C}$ at a heat rate of $5^{\circ} \mathrm{C} / \mathrm{min}$. Degradation of plastic bits initiated around $325-352^{\circ} \mathrm{C}$ and maximum of it has occurred at $419^{\circ} \mathrm{C}$. The vapors are condensed and collected as WPO. Utmost care was taken to aloof polyvinyl chloride waste in this pyrolysis process as it produces harmful and toxic gases like hydrogen chloride ${ }^{15}$. The vital chemical compounds of WPO are given in Table 1 and physiochemical properties of WPO are given in Table 2. 
Table 1: Composition of waste plastic oil

\begin{tabular}{lc}
\hline Compound name & Composition (\%) \\
\hline 1-Dodecanol & 10.9 \\
4-Octadeconol & 11.02 \\
Spirol & 9.836 \\
Xylofuranose & 9.20 \\
2.5-Dimethyl-4-benzyl-pyridine & 10.59 \\
Z-5-Methyl-6-heneicosen & 8.05 \\
2,2,9-Trimethyldec-5-ene & 5.93 \\
\hline
\end{tabular}

combustion precursor. Stock of ignition precursors ameliorates ignitability and consequently the cetane number. In this way, EHN enhances the possibility of ignition in this manner improves the ignition quality, apparent ignitability and cetane number of the fuel. Piston bowl profile.

To enhance the turbulence effect in combustion chamber, standard hemispherical combustion chamber (HCC) is modified to toroidal

Table 2: Properties of test fuels

\begin{tabular}{lcccc}
\hline Property & Diesel & WPO & WPOCA & ASTM method \\
\hline Density @ $15^{\circ} \mathrm{C}\left(\mathrm{kg} \mathrm{m}^{-3}\right)$ & 0.835 & 0.893 & 0.862 & D4052 \\
Calorific value $\left(\mathrm{MJ} \mathrm{kg}^{-1}\right)$ & 45.4 & 41.2 & 41.8 & D240 \\
Kinematic viscosity $(\mathrm{cSt})$ & 2.15 & 3.12 & 2.78 & D445 \\
Flash point $\left({ }^{\circ} \mathrm{C}\right)$ & 49 & 58 & 56 & D93 \\
Boiling point $\left({ }^{\circ} \mathrm{C}\right)$ & $180-330$ & $120-375$ & - & D7169-16 \\
Self ignition temperature $\left({ }^{\circ} \mathrm{C}\right)$ & 210 & 261 & 252 & D1929-16 \\
Cetane number & 53 & 31 & 42 & D4737 \\
Oxygen content $(\mathrm{wt} \%)$ & 0.03 & 4.31 & 4.4 & - \\
\hline
\end{tabular}

\section{Composite additive}

Many types of fuel additives like oxygenate, antioxidants, organic compounds, antiknock agents, combustion improvers etc., have been used along with diesel and alternative fuels either to lessen emissions or to improve engine performance. Despite the fact that a wide assortment of fuel additives has been devised for alternative fuels ${ }^{16}$, exceptional additive has not yet been developed for neat WPO. Based on comparison of physiochemical properties of WPO with diesel, those properties of WPO which are inferior to diesel cannot be improved with single additive. In this work, a composite additive, which is a mixture of 2 additives (soy lecithin + 2-ethylhexyl nitrate), is used. Soy lecithin, a bio-additive known for its surfactant and emulsifying properties. Phospholipids present in soy lecithin are the principal surface active agent and also an excellent emulsifier apart from dispersing agent. The amount of soy lecithin was optimized as $0.2 \%$ using critical micelle concentration method. Another property that is inferior in WPO to diesel is cetane number. In this study, 2-ethylhexyl nitrate (EHN) (CAS: 27247-96-7) is chosen from among various cetane improvers. The molecular formula is $\mathrm{C}_{8} \mathrm{H}_{17} \mathrm{NO}_{3}$ in which one hydrogen atom is replaced with a nitrate radical. It is steady at room temperature and decomposes within the cylinder after injection. EHN decomposes at 550-650K yielding hydroxyl radical, which is a combustion chamber with spherical grooves (TSG). The bowl volume was kept consistent for both configurations with the goal that compression ratio should be same. It is believed that TSG geometry of piston bowl increases the flow velocity and in turn creates higher swirl. HCC and TSG profiles are shown in Fig. 1(a) and Fig. 1(b) respectively.

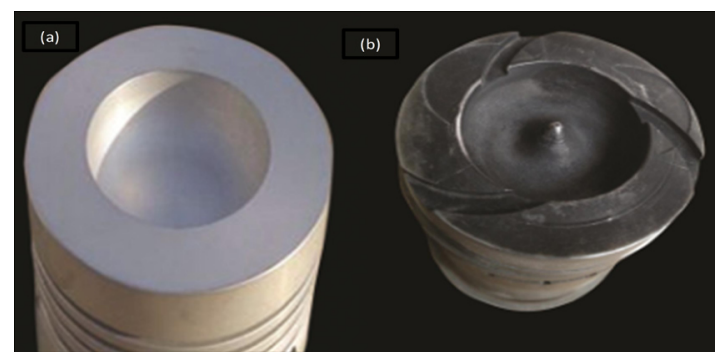

Fig. 1. Piston bowl (a) standard HCC, (b) modified TSG

\section{EXPERIMENTAL}

The test rig for this study is a $5.2 \mathrm{~kW}$ diesel engine of model TV1, Kirloskar make. This engine is coupled with an eddy current dynamometer. Instruments needed to measure combustion performance and emanation characteristics such as AVL H12D pressure transducer, AVL 364 angle encoder, AVL Digas 444 gas analyzer, AVL make smoke meter are installed onto the test rig. AVL INDI MICRA-602-T10602A version V2.5 interfaces for online analysis. The detailed description of setup 
is presented $\mathrm{in}^{11}$ and alongside, specifications of engine are appeared in Table 3. Fuels used for test are diesel, WPO and WPOCA $(97.8 \%$ WPO+0.2\% soy lecithin $+2 \% E H N$ ) and the physiochemical properties of test fuels are given in Table 2 . Standard operating procedure has been followed in conducting experiments. Tests were carried out with diesel at various loads using $\mathrm{HCC}$ piston. These values are utilized as baseline all through for correlation. Then, tests were conducted with diesel, WPO and WPOCA using $\mathrm{HCC}$ and TSG pistons at $20 \%, 40 \%, 60 \%, 80 \%$ and $100 \%$ load. Engine was kept running for $20 \mathrm{~min}$. at every load to stabilize and readings were recorded. For each refueling with other blends, engine was kept running for $30 \mathrm{~min}$. to consume the fuel entrapped in fuel lines. Repeatability was ensured by replicating

Table 3: Engine specifications

\begin{tabular}{ll}
\hline Make and model & Kirloskar, TV1 \\
\hline Number of cylinders & 1 \\
Bore, mm & 87.5 \\
Stroke, mm & 110 \\
Piston bowl & Standard: \\
& Hemispherical \\
& Modified: \\
& Toroidal spherical \\
Compression ratio & groove \\
Rated power, kW & $17.5: 1$ \\
Rated speed, rpm & 5.2 \\
Fuel injection type & 1500 \\
Number of nozzle holes & Direct injection \\
Fuel injection pressure, MPa & 3 \\
Fuel injection timing, ${ }^{\circ}$ CA bTDC & 22 \\
Dynamometer & Eddy current, 7.5 \\
& kW, 1500-3000 \\
& rpm, air cooled \\
& with loading unit \\
Load measurement & Direct coupling, \\
& Strain gauge \\
\hline
\end{tabular}

the experiments thrice.

\section{RESULTS AND DISCUSSION}

\section{Combustion characteristics}

In-cylinder pressure and heat release rate (HRR)

In-cylinder pressure as well as HRR variations at $100 \%$ and $80 \%$ load, presented in Fig. 2(a) and 2(b) respectively. Recording of the in-cylinder pressure as well as HRR data is done in a contiguous file, generated by the data acquisition system. In-cylinder pressure rate values become higher with load for all test fuels. In-cylinder pressure rise starts a little later for WPO and WPOCA than for diesel with HCC and TSG. Marginal delay and slightly higher peak pressure are observed for WPO in HCC and TSG than other fuels.

At $100 \%$ load and $80 \%$ load, the two phases of combustion i.e. premixed combustion phase and diffusion combustion phase are obvious with diffusion combustion phase reducing at $80 \%$ load. Considering each load, peak of premixed combustion phase is substantially higher and sharper with WPO against diesel. This leads to higher maximum pressure attributable to slower preparation rate of fuel air mixture for combustion during the diffusion phase ${ }^{17}$. For all test fuels, peak cylinder pressure for TSG is higher than HCC. TSG profile has predominant influence on the swirl and turbulence. Peak pressure for WPOCA with TSG is slightly lower than diesel with TSG which might be due to reduced delay period. Soy lecithin present in composite additive goes about as surfactant and tends to diminish surface tension of fuel which specifically relates to internal pressure and compressibility of fuel ${ }^{18}$. With addition of EHN in composite additive to WPO, nitrate molecules breakdown for better fuel decomposition.

HRR variations for $100 \%$ load and $80 \%$ load has almost the same trend for all test fuels, unlike in low load case, a 'hesitant hump' has been noticed after the first rise for all test fuels which may be attributed to the deliberate delay in static injection timing. Ignition delay period is influenced by factors like chemical composition of fuel, availability of fuel air etc., From Fig. 2(a) and Fig. 2(b), HRR with all test fuels for TSG is higher than that of HCC. TSG generates a stronger squish and subsequently for better combustion ${ }^{19}$.

The maximum HRR for WPO with HCC and TSG is higher than other test fuels. The higher viscosity of WPO deteriorates the spray atomization during premixed combustion phase and lengthens combustion delay. Albeit, ignition delay is shortened by use of composite additive in WPOCA. Fuel droplet surface area and volume along with bulk modulus are of essential significance for evaporation and combustion which predominantly influence ignition delay period. Soy lecithin in composite additive acts 
as surfactant bringing about speedier vaporization and atomization of fuel, resulting in reduced ignition delay period. Also, the higher volatility of EHN increases dissemination rates of fuel vapor which

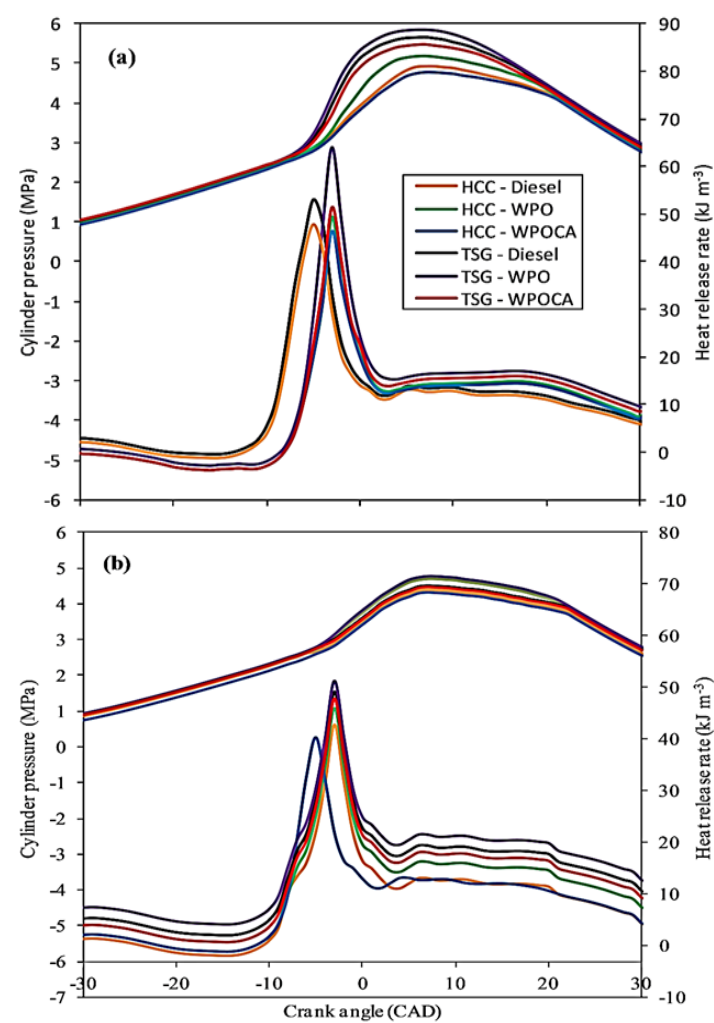

Fig. 2. Combustion analysis as a function of crank angle for all test fuels with HCC and TSG (a) at $100 \%$ load (b) at $80 \%$ load

accelerates mixture preparation before ignition.

Ignition delay

Variations of ignition delay period for all fuels with HCC and TSG are compared in Fig. 3. For all experimental fuels along with combustion chamber profiles, diminishment in ignition delay period enhances with enhancement in load and this is because of elevated combustion chamber and attenuated exhaust gas adulteration at higher loads. For WPO, minimal compressibility along with higher viscosity might have led for the enhancement in ignition delay. While, the ignition delay period is abbreviated in WPOCA with TSG and HCC which might be attributed to elevated fuel bound oxygen and is additionally decreased because of the diminishment in physical delay period by augmenting air fuel mixing in TSG.

\section{Start of combustion timing (SOC)}

The analysis of cylinder pressure diagram uncovers the SOC regarding crank angle where pressure in regards to crack angle abruptly changes its incline following fuel injection. SOC has critical impact on the combustion phase and temperature. Fig. 4 demonstrates the SOC of various experimental fuels with HCC and TSG. It is observed that, SOC timing steadily advances with enhancement in load with HCC and TSG. This might be ascribed to the enhancement in compression temperature which abbreviates the ignition delay period. It additionally can be seen that the SOC turns out to be prior with

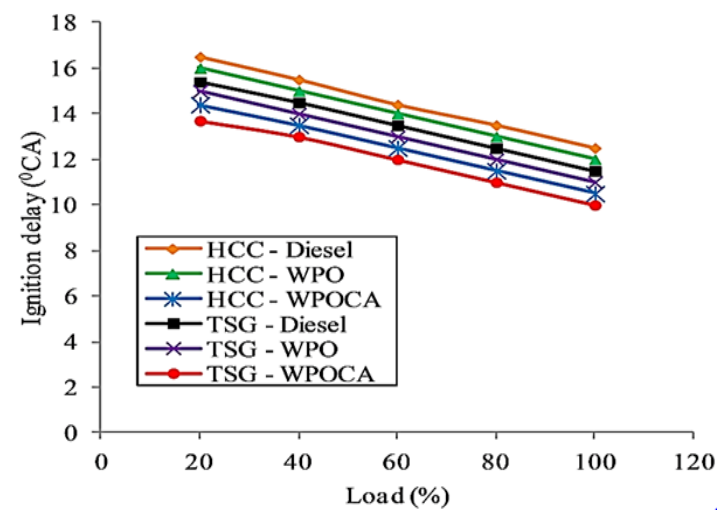

Fig. 3. Ignition delay variation as a function of load

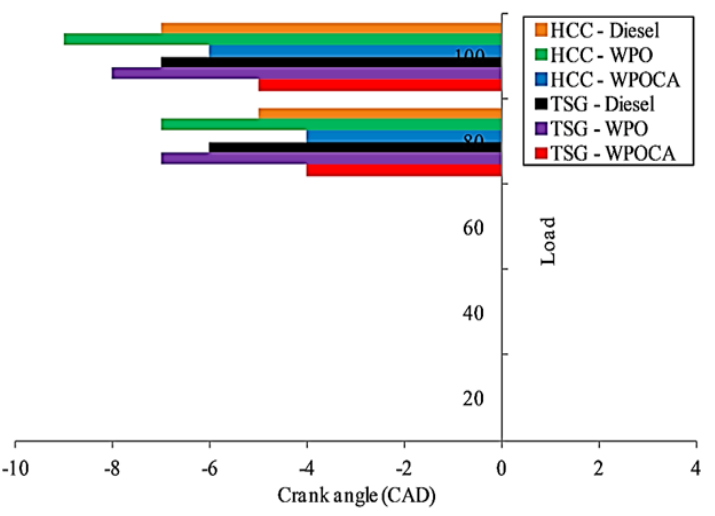

Fig. 4. SOC timing with HCC and TSG for all test fuels under different load conditions

TSG than HCC at $100 \%$ load and $80 \%$ load.

Peak of in-cylinder pressure and peak HRR

The illustration of peak in- cylinder pressure and peak HRR for all experimental fuels with HCC and TSG is presented in Fig. 5(a) and Fig. 5(b). Peak in- cylinder pressure and peak HRR are higher for WPO in HCC and TSG than other fuels. It is ascribed that majority of the portion of fuel burns during diffusion combustion phase and peak HRR is additionally accomplished at diffusion combustion phase. The fuel bound oxygen may advance the combustion procedure and recompenses for 
the impact of low calorific value to WPO. While the ignition delay period decreases with load for WPOCA, SOC occurs later with respect to neat diesel. SOC is delayed as a consequence of synergy of the lower dynamic injection timing thus leading to lower in- cylinder pressure and HRR.

\section{Peak of in-cylinder temperature}

Mean in- cylinder gas temperature variations with load for all experimental fuels using HCC and TSG are compared in Fig. 5(c). The in-cylinder mean gas temperature increase with increase in the load for HCC and TSG. Peak of in- cylinder temperature is generally influenced by the HRR. It also can be seen that in- cylinder temperature with WPOCA is lower than that of WPO. In- cylinder temperature has
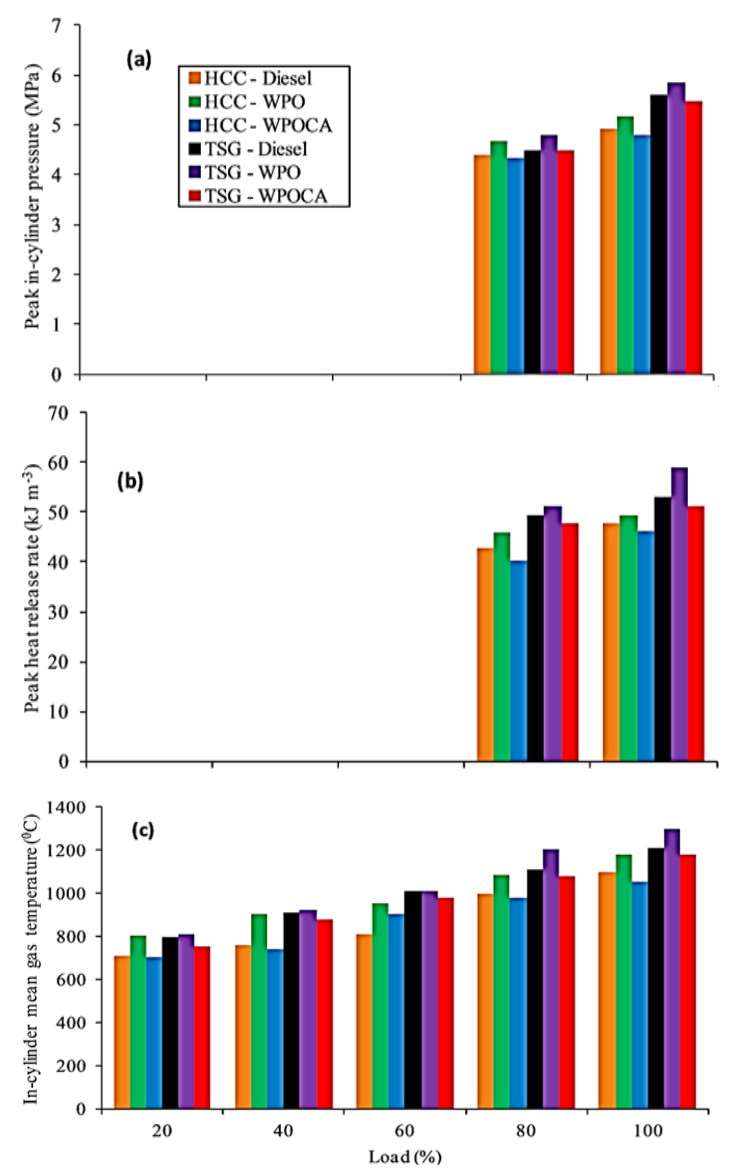

Fig. 5. Variations of in-cylinder combustion parameters as a function of load for all test fuels with HCC and TSG (a) peak in-cylinder pressure, (b) peak HRR, (c) mean gas temperature very critical effect on the formation of $\mathrm{NO}_{x}$.

Emission characteristics

Oxides of nitrogen ( $\mathrm{NO}_{\mathrm{x}}$ )

Figure 6(a) shows NOx variations with respect to load using HCC and TSG. NOx is produced at elevated temperatures and it relies upon combustion temperature and amount of oxygen. WPO shows an increase of $11.97 \%$ of $\mathrm{NO}_{\mathrm{x}}$ emission with $\mathrm{HCC}$ and $12.56 \%$ with TSG than diesel. This might be ascribed to higher HRR and longer ignition delay period with WPO. WPO contains $3.31 \%$ of oxygen (Table 2), which assumes an essential part in $\mathrm{NO}_{\mathrm{x}}$ emanation. Furthermore, with increase in combustion temperature in TSG, $\mathrm{NO}_{\mathrm{x}}$ emission is higher in TSG than HCC. It can also be seen that $\mathrm{NO}_{x}$ emission using WPOCA reduced by $8.72 \%$ with HCC and $16.79 \%$ with TSG than WPO. The reduced HRR and shorter ignition delay period causes drop in peak combustion temperature, accordingly cutting down $\mathrm{NO}_{\mathrm{x}}$ emanation. When compared with diesel, $\mathrm{NO}_{\mathrm{x}}$ emission for WPOCA increased by $4.28 \%$ with HCC and $5.75 \%$ with TSG. The presence of nitrogen content in soy lecithin and EHN of composite additive contribute to the increase in prompt $\mathrm{NO}_{\mathrm{x}}$ formation ${ }^{18}$. Be that as it may, improved mixture formation leading to increased combustion temperature in TSG along with the availability of oxygen in WPO and WPOCA may be attributed for increased $\mathrm{NO}_{\mathrm{x}}$ emission ${ }^{20}$.

\section{Carbon monoxide and equivalence ratio}

Figure 6(b) shows $\mathrm{CO}$ emission as well as equivalence ratio as a function of load for HCC and TSG for all test fuels. The formation of $\mathrm{CO}$ is essentially because of inadequate combustion which is aggravated due to insufficient oxygen and equivalence ratio. $\mathrm{CO}$ emanation diminishes with increment in load upto $80 \%$ for all fuels and suddenly increases ahead of $80 \%$ load. This could be of burning up excess fuel to meet the load and speed conditions ${ }^{21}$.

Under full load conditions, WPO emits lower CO emission by $6.34 \%$ with HCC and $10.6 \%$ with TSG than diesel. The local rich and lean mixture formed in the combustion chamber has led to the reduction in $\mathrm{CO}$. As more amount of oxygen is available in WPO, this improved the conversion of $\mathrm{CO}$ into $\mathrm{CO}_{2}$. The variations of equivalence ratio confirms to this. It can be interesting to note that for WPOCA, $\mathrm{CO}$ emission decreased by $13.55 \%$ with $\mathrm{HCC}$ and $17.74 \%$ with TSG than diesel. This can be attributed to the surfactant action of composite additive for better atomization and vaporization of fuel along with swirl motion all through the combustion chamber 
bringing about complete combustion ${ }^{15}$.

\section{Hydrocarbon}

The HC emission for HCC and TSG using WPO and WPOCA are compared with diesel and are shown in Fig. 6(c). HC emanation for HCC and TSG has reduced over the whole range of loads when operated with WPO and WPOCA. This may be due to availability of excess oxygen in WPO and WPOCA It is also observed that $\mathrm{HC}$ emission reduced by $8.62 \%$ with $\mathrm{HCC}$ and $15.72 \%$ with TSG for WPOCA than diesel. Better mixing of WPOCA and air along with enhanced swirl might have led to complete combustion. Besides, oxygen present in composite additive likewise bolsters combustion process

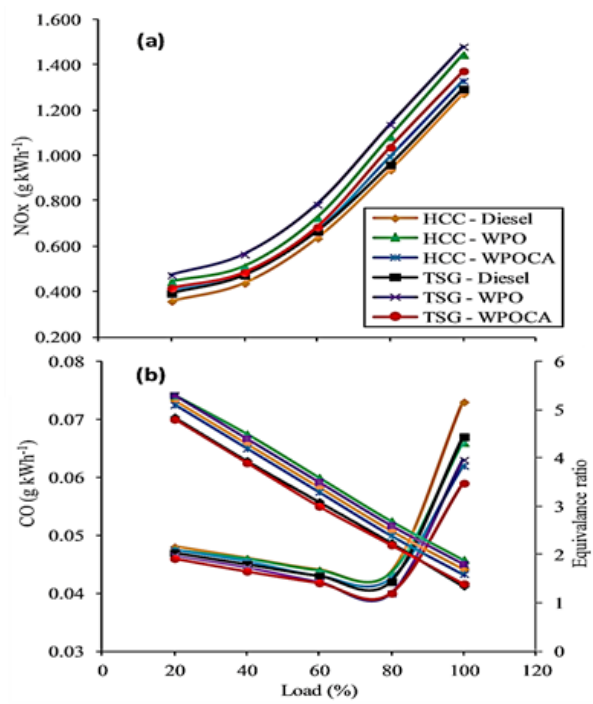

subsequently decreasing $\mathrm{HC}$ emanation ${ }^{22,23}$. Smoke

Smoke emission is unequivocally identified with diffusive combustion which for the most part happens in rich zone at high temperatures ${ }^{24}$ Fig. 6(d) shows smoke emission variations for $\mathrm{HCC}$ and TSG with all test fuels. Smoke emission for WPO and WPOCA is found to be lower than diesel for both HCC and TSG. The presence of excess oxygen in WPO and WPOCA makes the fuel air mixture leaner consequently combustion occurs by making use of oxygen in rich zones resulting in a decreased smoke formation. Smoke emission for WPOCA with TSG is lower than other test fuels which might be credited to adequate combustion because of better mixing of fuel with air and the availability of oxygen

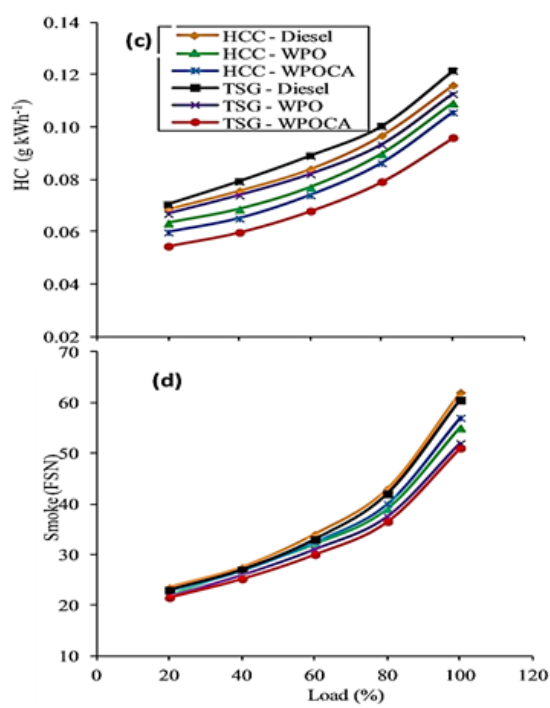

Fig. 6. Emission evaluation as function of load for all test fuels using $\mathrm{HCC}$ and TSG (a) $\mathrm{NO}_{\mathrm{x}}$, (b) $\mathrm{CO}$ and equivalence ratio, (c) $\mathrm{HC}$, (d) Smoke

in composite additive along with that in WPO.

\section{CONCLUSION}

An experimental study is led to assess diesel engine combustion and emission characteristics using HCC and TSG combustion chambers with WPO, WPOCA and compared with diesel. More explicitly it is revealed that, with use of WPO and WPOCA with HCC and TSG, the following hold:

1. The physiochemical attributes of WPO and WPOCA are adequate and propitious to be used as fuels on diesel engine.

2. Composite additive has remarkable effect on the physiochemical properties of WPO. Cetane number has increased from 31 in WPO to 42 in WPOCA.
3. TSG combustion chamber showed higher combustion chamber temperature because of better air movement thereby reducing ignition delay period. This has significant effect with WPOCA for better combustion.

4. $\quad \mathrm{NO}_{x}$ emission using WPOCA reduced by $8.72 \%$ with HCC and $16.79 \%$ with TSG than WPO. For WPOCA, CO emission decreased by $13.55 \%$ with HCC and $17.74 \%$ with TSG than diesel. $\mathrm{HC}$ emission reduced by $8.62 \%$ with HCC and $15.72 \%$ with TSG for WPOCA than diesel. EHN being highly volatile, WPOCA reduced smoke emission by $14.5 \%$ than diesel in TSG.

Thus, the test results suggest that for the long term running, the addition of composite additive 
to neat WPO lead to smooth running of the engine without any trouble. The results also suggest that improvements in engine-out emissions and better performance may be obtained from current diesel engine by careful matching of combustion geometry and fuel modifications.

\section{ACKNOWLEDGMENT}

the technical paper to the current form.

\section{REFERENCES}

1. Luís, P. A.; António, A.; Edmilson, M.; Nelson, M. Sustainable Energy Technol. Assess., 2014, 7, 101-110.

2. Hadi, A. J.; Abdulkadir, H. K.; Hadi, G. J.; Yusoh, K. B.; Hasany, S. F. Orient. J. Chem., 2018, 34(2), 1069-1077.

3. Nixon, J.D.; Dey, P. K.; Ghosh, S. K. Sustainable Energy Technol. Assess., 2017, 21, 23-32.

4. Singh, D. P.; Maurya, N. S. Orient. J. Chem., 2016, 32(3), 1373-1380.

5. Prabhahar, M.; Sendilvelan, S.; Xavier, J. F. Orient. J. Chem., 2017, 33(6), 2937-2941.

6. Kalargaris, I.; Tian, G.; Gu, S. Fuel., 2018, 211(1), 797-803.

7. Miandad, R.; Barakat, M. A.; Rehan, M.; Aburiazaiza, A. S.; Ismail, I. M. I.; Nizami, A. S. Waste Manage., 2017, 69, 66-78.

8. Ananthakumar, S.; Jayabal, S.; Thirumal, P. J.Braz. Soc. Mech. Sci. Eng., 2017, 39(1), 19-28.

9. Devaraj, J.; Robinson, Y.; Ganapathi, P. Energy., 2015, 85(1), 304-309.

10. Damodharan, D.; Sathiyagnanam, A. P.; Rana, D.; Kumar, B. R.; Saravanan, S. Energ Convers. Manage., 2017, 131(1), 117-126.

11. Bridjesh, P.; Periyasamy, P.; Krishnachaitanya, A. V.; Geetha, N. K. Sustain Environ. Res.,
The authors would like to thank Mr.M Rajasekhar Reddy, Secretary, MLR Institute of Technology for having given the necessary facilities to publish the findings of this research in the form of technical paper. The author also express gratitude to his superiors, peers and colleagues who were instrumental in providing their rich experience, suggestions and guidance which resulted in shaping

2018, 28(3), 142-147.

12. Yadav, P.; Saravanan, C.; Edward, J.; Perumal, R. SAE Technical paper., 2015, 2015, 01-0378.

13. Taghavifar, H.; Khalilarya, S.; Jafarmadar, S. Energ Convers. Manage., 2014, 85, 20-32.

14. Brijesh, P.; Abhishek, S.; Sreedhara, S. SAE Technical paper., 2015, 2015, 01-0402.

15. Shafferina, D. A. S.; Faisal, A.; Wan, M. A. W. D.; Mohamed, K. A. Energ Convers. Manage., 2016, 115, 308-326.

16. Issaka, S. A.; Nour, A. H.; Yunus, R. M. Orient. J. Chem., 2015, 31(3), 1717-1722.

17. Mani, M.; Nagarajan, G.; Sampath, S. Energy., 2011, 36(1), 212-219.

18. Pinkesh, R. S.; Gaitonde, U. N.; Ganesh, A. Renewable Energy., 2018, 115, 685-696.

19. Jaichandar, S.; Annamalai, K. Energy., 2012, 44(1), 633-640.

20. Atmanli, A. Fuel., 2016, 172, 209-217.

21. Purushothaman, K.; Nagarajan, G. Renewable Energy., 2009, 34(1), 242-245.

22. Kumar, S.; Prakash, R.; Murugan, S.; Singh, R.K. Energ Convers. Manage., 2013, 74, 323-331.

23. Bhaskar, K.;Sendilvelan, S.; Nagarajan, G.;Sampath, S. Sustain Environ. Res., 2017, 27 (6), 283-290.

24. Pragyan, P. P.; Shakti, P.J.; Saroj, K. A.; Harish, C. 